\title{
REFLEXÕES SOBRE POLÍTICAS EDUCATIVAS, BNCC E FORMAÇÃO DOCENTE
}

\author{
REFLEXIONES SOBRE POLÍTICAS EDUCATIVAS, BNCC Y FORMACIÓN DEL \\ PROFESORADO
}

\author{
THOUGHTS ON EDUCATIONAL POLICIES, BNCC AND TEACHER \\ EDUCATION
}

\author{
Rosália Maria Netto PRADOS ${ }^{1}$ \\ Rodrigo Avella RAMIREZ ${ }^{2}$ \\ Sonia Maria ALVAREZ ${ }^{3}$
}

RESUMO: Este artigo trata de uma discussão sobre políticas de ensino de línguas no cenário contemporâneo para uma reflexão sobre a formação do professor da área de Letras. Fundamenta-se em teorias linguísticas e nas políticas educacionais, além de se apresentarem também estudos sobre o ensino de línguas no Brasil que refletem diretamente no processo de ensino-aprendizagem que se constituiu ao longo do processo histórico da educação brasileira. Tem como objetivos, apresentar o cenário contemporâneo do ensino de línguas; e descrever discursos político-educacionais de ensino e de formação do professor. A metodologia é a de uma pesquisa descritiva, de abordagem qualitativa, sobre teorias linguísticas e diretrizes curriculares do curso de Letras, para uma reflexão sobre as práticas linguísticas contemporâneas e políticas educacionais de formação e de ensino de línguas.

PALAVRAS-CHAVE: Políticas educacionais. Formação do professor. Ensino-aprendizagem.

RESUMEN: Este artículo aborda una discusión sobre las políticas de enseñanza de idiomas en el escenario contemporáneo para una reflexión sobre la formación de docentes en el área de las letras. Se basa en teorías lingüisticas y políticas educativas, además de presentar estudios sobre la enseñanza de idiomas en Brasil, que reflejan directamente el proceso de enseñanza-aprendizaje y que se constituyó a lo largo del proceso histórico de la educación brasileña. Sus objetivos son presentar el escenario contemporáneo de enseñanza de idiomas; $y$ describir discursos político-educativos de enseñanza y formación docente. La metodología es la de una investigación descriptiva, con un enfoque cualitativo, sobre teorías lingüisticas y

\footnotetext{
${ }^{1}$ Centro Estadual de Educação Tecnológica Paula Souza (CEETEPS), São Paulo - SP - Brasil. Professora e Pesquisadora no Programa de Pós-graduação em Gestão e Desenvolvimento da Educação Profissional. Doutorado em Semiótica e Linguística Geral (USP). ORCID: https://orcid.org/0000-0003-2138-8422. E-mail: rosalia.prados@gmail.com

${ }^{2}$ Centro Estadual de Educação Tecnológica Paula Souza (CEETEPS), São Paulo - SP - Brasil. Professor e Pesquisador no Programa de Pós-graduação em Gestão e Desenvolvimento da Educação Profissional. Doutorado em Educação, Arte e História da Cultura (MACKENZIE). ORCID: https://orcid.org/0000-0001-8468-2851. Email: roram1000@hotmail.com

${ }^{3}$ Faculdade de Tecnologia de São Paulo (FATEC), Itaquaquecetuba - SP - Brasil. Doutorado em Linguística Aplicada do Ensino de Línguas (PUC-SP). ORCID: https://orcid.org/0000-0002-6415-5138. E-mail: sonia.alvarez@uol.com.br

RPGE- Revista on line de Política e Gestão Educacional, Araraquara, v. 25, n. 1, p. 86-102, jan./abr. $2021 . \quad$ e-ISSN:1519-9029 DOI: https://doi.org/10.22633/rpge.v25i1.13628 (c) BY-NC-SA 
pautas curriculares para el curso de formación en lenguas, para una reflexión sobre las prácticas lingüisticas contemporáneas y las políticas educativas de formación y enseñanza de idiomas.

PALABRAS CLAVE: Politicas educativas. Formación del profesorado. Enseñanzaaprendizaje.

ABSTRACT: This article deals with a discussion about language teaching policies in the contemporary setting for a reflection on the education of the teacher of the Letters area. It is based on linguistic theories and educational policies, as well as on studies on language teaching in Brazil, which reflect directly on the teaching-learning process and was constituted throughout the historical process of Brazilian education. Its objectives are to present the contemporary scenario of language teaching; and describe the political-educational discourses of teaching and teacher education. The methodology is that of a descriptive research, of qualitative approach, on linguistic theories and the curricular guidelines for the Course of Letters, for a reflection on the contemporary linguistic practices and the educational policies of education and the teaching of languages.

KEYWORDS: Educational policies. Teacher education. Teaching-learning.

\section{Introdução}

Propõe-se uma reflexão sobre a formação do professor de línguas e o contexto sociocultural e educacional em que esse sujeito se insere no cenário contemporâneo. Discutese, neste artigo, como as políticas linguísticas e de ensino de língua materna e de língua estrangeira configuram-se nesse contexto, além das políticas educacionais de ensino e de formação do professor dessa área. Tais políticas, decorrentes da configuração dos estudos de Língua Portuguesa e de Língua Estrangeira no Brasil, refletem diretamente no processo de ensino-aprendizagem que se constituiu ao longo do percurso histórico da educação brasileira.

Justificam-se essas reflexões, pois uma discussão sobre políticas linguísticas já se caracterizava, ainda que de forma incipiente, no que se refere à Língua Portuguesa, desde os primórdios da colonização brasileira, a partir do século XVI. No período romântico, no século XIX, por exemplo, diferentes explicações e conflitos se estabeleceram entre escritores brasileiros e portugueses e, no início do século XX, poetas modernistas, como Oswald de Andrade, Manuel Bandeira, dentre outros, já enfocavam o conflito do uso da língua que caracterizava o falar brasileiro, o que sempre inflamou muitas discussões. No que se refere ao uso da língua, a constituição da identidade do brasileiro se forma e se desenvolve nesse panorama histórico, político, econômico e social (PRADOS; ALVAREZ, 2016). 
Segundo Prados e Alvarez (2016), na mídia, em 2011, em importante emissora nacional de televisão, foram focalizados diferentes usos da linguagem verbal, apresentados em um livro didático, aprovado pelo Programa Nacional do Livro Didático (PNLD, 2011), e interpretados como "erros". De acordo com as autoras, foi possível verificar, de um lado, a concepção de que o brasileiro vê a língua segundo o padrão formal como o modelo correto e de outro lado, a dos estudiosos linguistas que focalizam questões de diferentes usos da língua, as variações linguísticas, mas essas ainda são apontadas, de um modo geral, por pessoas e representantes da sociedade, como deficiências linguísticas. Assim, evidencia-se uma política linguística do uso do padrão da escrita e que não aceita os diferentes falares dos brasileiros.

Segundo Cavalcanti (2013), a aprovação do referido livro didático Por uma vida melhor foi fortemente contestada e rejeitada por grande parte de jornalistas que acusaram o livro de fazer apologia do erro. No entanto, de acordo com Cavalcanti (2013), são veiculados textos de linguistas e especialistas que, fundamentados em pesquisas linguísticas nas últimas décadas, rebatem os argumentos apresentados pelos críticos do livro. A autora, ainda, refere-se à lei contra o estrangeirismo, do deputado Aldo Rebelo, em que se abriu um espaço para que outras vozes, além das que são veiculadas na mídia, expusessem seus pontos de vista.

Configura-se, assim, uma polêmica que mais uma vez vai revelar o pouco (ou nenhum) conhecimento da imprensa e da sociedade em geral em relação a aspectos da língua, incluindo seu ensino, como este deve ser promovido e que "conteúdo" privilegiar.

Nesta discussão, em que se trata de reflexões sobre formação do professor de línguas, enfatizam-se as políticas educacionais de documentos oficiais, em que se pode evidenciar uma certa obsolescência do curso de licenciatura em Letras. Para essa discussão, a metodologia, de natureza descritiva e abordagem qualitativa, constitui-se de um estudo dos discursos subjacentes às políticas-educacionais e pedagógicas, além de uma discussão sobre a formação no que se refere à carreira docente do profissional de Letras.

Propõe-se, nesta discussão, uma perspectiva de análise do discurso que possibilita a reconstrução do processo de produção de sentido dos discursos da educação e respectivos discursos político-educacionais que, por sua vez, refletem os sistemas de valores da sociedade atual. Assim é possível o estudo do saber compartilhado sobre o ensino da Língua Portuguesa e de Língua Estrangeira no Brasil.

Considera-se, portanto, nesta análise, que os discursos constituem redes de significação e estão inseridos num processo dinâmico, esses podem ser motivados por um determinado fato social, numa determinada época e espaço, e produzir sentidos únicos nesse determinado 
contexto (PRADOS; BONINI, 2017). Portanto, as políticas educacionais se constituem a partir de valores expressos em documentos e em leis e essas caracterizam os discursos políticoeducacionais e político-pedagógicos.

Para uma reflexão sobre a formação do professor na área de Letras, diante das teorias linguísticas, exigências socioculturais, anseios e expectativas, é necessário pensar-se o discurso manifestado no contexto educacional, que está subjacente nos documentos oficiais, como um dos discursos constituintes dotado de maior autonomia e que confere sentido aos atos coletivos e de classe, ou seja, às zonas de falar (MAINGUENEAU, 2008).

O discurso educacional, de acordo com Maingueneau (2008), organiza-se em torno de textos ligados a instituições que garantem sua necessidade de interpretação e de autorização. Assim, o discurso que se apresenta em documentos oficiais sustenta-se em sistemas de valores que, por sua vez, reproduzem não só os discursos políticos-educacionais, mas também outros discursos sobre cidadania, vontade política, ética, além dos discursos político-pedagógicos.

Nesta discussão, portanto, consideram-se os discursos político-educacionais, questões de uso e políticas linguísticas, além de estudos de teorias linguísticas que evidenciam a necessidade de se rever constantemente a estrutura curricular do curso de Letras para a formação do professor. E, para uma análise descritiva, consideram-se, também, as políticas de ensino nos documentos oficiais, como a Base Nacional Comum Curricular, BNCC (BRASIL, 2018), já que diretrizes curriculares e políticas educacionais e de ensino impactam na carreira docente na área de Letras.

\section{Políticas educacionais e o curso de Letras no cenário contemporâneo}

Vale lembrar que os planos e as propostas curriculares tornam-se parâmetros, modelos a serem seguidos, com a ação como consequência. As políticas públicas culturais e educacionais produzidas no contexto contemporâneo e voltadas ao ensino de Língua Portuguesa e de Língua Estrangeira se configuram como preocupações efetivas voltadas à melhoria da qualidade da educação, no que se refere ao ensino-aprendizagem de línguas.

Hoje, o ensino-aprendizagem de línguas está vinculado à inserção social, exercício da cidadania, com as atuais políticas linguísticas e as questões próprias das linguagens. De acordo com Geraldi (2008), nos estudos linguísticos contemporâneos, a língua é marcada pela fala, com questões de análise sobre a dêixis, as modalidades, a performatividade, a polissemia, a argumentação, a implicitação, a polifonia e a heterogeneidade. É necessário, portanto, considerar nesses estudos, as instâncias sociais para o ensino de línguas.

RPGE- Revista on line de Política e Gestão Educacional, Araraquara, v. 25, n. 1, p. 86-102, jan./abr. $2021 . \quad$ e-ISSN:1519-9029 DOI: https://doi.org/10.22633/rpge.v25i1.13628 
Esse novo quadro se justifica, pois, a função tradicional do ensino, a instrumental, resultou em diferentes deficiências, em função do uso oral rudimentar, da língua fechada em grupos sociais, da falta de domínio de estruturas linguísticas e do léxico. A escola, portanto, deve propiciar uma diversidade de interações, com diferentes usos da língua em instâncias privadas e públicas, com a concepção de linguagem como atividade constitutiva, cujo locus de realização é a interação verbal, com o uso linguístico voltado à leitura e à produção de textos, com a utilização da Pragmática, da Análise de Discurso e da Sociolinguística, novas correntes linguísticas aplicadas às metodologias de ensino da língua.

O ingresso em um curso de Letras, nos dias atuais, significa, via de regra, conviver com uma estrutura acadêmica, que ainda mantém valores e conteúdo não condizentes com o desenvolvimento social e tecnológico do momento. Tradicionalmente, o ingresso nesse curso tinha por objetivos conhecer os ideais aristocráticos, elitistas com a valorização da literatura clássica. Ao longo do tempo, outros ideais foram incorporados aos objetivos do curso, como os estudos científicos linguísticos, ainda que de forma desordenada, sem um planejamento efetivo e aplicável do currículo (BAGNO, 2013).

Segundo Souza, Pereira e Costa (2012), entre os objetivos dos cursos de licenciaturas no Brasil, está o de formar professores que apresentem habilidades e competências técnicas, além das pedagógicas, para conduzir o processo de ensino-aprendizagem e para se adequar às mudanças e aos desafios, no âmbito social e profissional, nas salas de aula das escolas brasileiras. Para isso, no curso de Letras, as novas teorias linguísticas, que tratam do uso da língua, dos falares, dos discursos e estão isoladas nos currículos como conteúdo, deveriam ser aplicadas ao ensino, não só de leitura e de escrita, mas também para identificar e valorizar os diferentes falares brasileiros.

Para se considerar um currículo que se aplique às exigências socioculturais contemporâneas, é necessário se pensar, não só nas mudanças que ocorrem na língua falada, sobre questões de uso, mas no contexto da comunicação e novos meios. A própria essência da ideia de educação, segundo Bauman (2010), tal como ela se formou, é questionada, assim como a solidez das coisas ou a solidez dos vínculos humanos.

Essas discussões se impõem no contexto contemporâneo em que o consumo exige sempre a busca de soluções novas em sistemas também novos. Na comunicação, por meio das tecnologias móveis, por exemplo, os usuários da língua apresentam novas relações de linguagem, variações linguísticas e isso constitui mais um desafio para o ensino de línguas. 
Para as políticas educacionais do Ministério da Educação (MEC) brasileiro que orientam e normatizam os cursos de formação de professores, as diretrizes e as propostas pedagógicas desses cursos devem estar em sintonia com as diretrizes de documentos oficiais, como por exemplo, os Parâmetros Curriculares Nacionais (PCN), Orientações Curriculares Nacionais $(\mathrm{OCN})$ e estaduais e a atual Base Nacional Comum Curricular (BNCC), à qual todos devem se adequar.

Segundo a BNCC (BRASIL, 2018), o componente curricular Língua Portuguesa retoma documentos e orientações curriculares, publicados nas últimas décadas, e busca atualizá-los em relação às pesquisas linguísticas recentes e mudanças nas práticas de linguagens em consequência do avanço das tecnologias digitais de informação e comunicação. E quanto à Língua Inglesa, por exemplo, a visão é a de que esta se torne um bem simbólico para falantes de todo o mundo, já que, ao assumir um status de língua franca, uma língua que se materializa em usos híbridos e marca-se pela fluidez, no contexto contemporâneo, abre-se para a invenção de novas formas de dizer, impulsionada por falantes pluri/multilíngues e características multiculturais (BRASIL, 2018).

Dessa forma, evidencia-se uma perspectiva enunciativo-discursiva de linguagem, já apresentada em outros documentos, como nos Parâmetros Curriculares Nacionais (PCN), nos quais a linguagem foi apresentada como um processo de interlocução que tem origem e se realiza nas práticas sociais existentes numa sociedade (BRASIL, 2018).

Segundo o discurso linguístico do atual documento, BNCC (BRASIL, 2018), nos PCN (BRASIL, 1998) já se podiam verificar as orientações sobre a centralidade do texto, como unidade de trabalho e abordagem de perspectivas enunciativo-discursivas, de forma a sempre relacionar os textos aos seus contextos de produção, além de propor o desenvolvimento de habilidades relacionado ao uso significativo da linguagem em atividades de leitura e produção de textos em diferentes mídias e semioses, ou diferentes linguagens.

Portanto, o novo documento considera as práticas contemporâneas de linguagem, e respectivos gêneros discursivos, além de se basear em concepções e conceitos já tratados em outros documentos, em orientações curriculares e em contextos variados de formação de professores. Tais concepções e conceitos dessa área, relativamente conhecidos em programas de formação são as referências sobre práticas de linguagem, discurso e gêneros discursivos/gêneros textuais, esferas/campos de circulação dos discursos (BRASIL, 2018).

O discurso político-educacional de Língua Portuguesa, segundo o que se apresenta no documento, sem essas considerações sobre os estudos do discurso do texto, não possibilitaria a 
participação social nas diferentes esferas da vida pública, do trabalho e pessoal de forma justa e igual. E, quanto ao estudo da Língua Inglesa, este pode possibilitar o acesso aos saberes linguísticos necessários para o engajamento e participação; contribuir para o agenciamento crítico e para o exercício da cidadania ativa, além de ampliar as possibilidades de interação e mobilidade, para a abertura de novos percursos de construção de conhecimentos e de continuidade nos estudos. A aprendizagem da Língua Inglesa apresenta esse caráter formativo, segundo essa perspectiva de educação linguística, consciente e crítica, na qual as dimensões políticas e pedagógicas se relacionam intrinsicamente (BRASIL, 2018).

Assim, de acordo com a BNCC, o texto, que pertence a um determinado gênero discursivo, que por sua vez, tem origem e circula nas diferentes práticas sociais, é a base para definição de conteúdo, habilidades e objetivos.

Dessa forma, o conhecimento sobre a língua, norma padrão e usos; sobre gêneros, textos e sobre diferentes linguagens, de acordo com a BNCC, devem ser mobilizados para o desenvolvimento das competências de leitura, produção de texto e tratamento das linguagens. Cabe, portanto, aos componentes curriculares Língua Portuguesa e Língua Inglesa possibilitarem ampliação dos letramentos, por meio das experiências linguísticas, a fim de que seja possível uma participação significativa e crítica em diferentes práticas sociais “permeadas/constituídas pela oralidade, pela escrita e por outras linguagens” (BRASIL, 2018, p. 66).

Para o curso de Letras, assim, a BNCC, os PCNs e as Orientações Curriculares Nacionais do Ensino Médio de Linguagens, Códigos e suas Tecnologias (respectivamente BRASIL, 2018; BRASIL, 1998; BRASIL, 2006) defendem que o ensino de língua seja baseado no trabalho com o texto e respectivos contextos de produção em detrimento do ensino baseado na decodificação de regras da gramática normativa.

Verifica-se que os discursos político-educacionais de formação do professor para o ensino da língua trazem, também, subjacentes sistemas de valores históricos, politicamente constituídos no contexto sociocultural, uma visão tradicional sobre o ensino de línguas com todos os desafios que se lhe impõem.

Dessa maneira, as propostas oficiais de ensino de línguas distanciam-se, também, de uma educação que assegure os direitos linguísticos do cidadão e da construção de sua cidadania. E os professores após o término do curso de Letras, segundo Prados e Alvarez (2016), não conhecem as teorias atuais que podem fundamentar as metodologias de ensino da língua, como 
a linguística aplicada, a análise do discurso, a teoria e a crítica literária e, nem mesmo, a tradição gramatical.

Segundo Paiva (2003), essa visão tradicional tem como causa o fato de que parte considerável de professores de ensino superior não se envolve com a formação docente, mas sim com um perfil de estudante voltado para o bacharelado. De um modo geral, pesquisadores não têm ciência sobre a realidade da própria formação do estudante em Letras, que será a de um professor de Ensino Fundamental e Médio.

Ainda, de acordo com Paiva (2003), em grande parte dos cursos de Letras, as atividades de pesquisa não são desenvolvidas no Brasil, e as instituições de ensino superior que têm programas de iniciação científica, com extensão ou monitorias, na área, são poucas.

E as políticas linguísticas para os cursos de Letras, geralmente, não conseguem adentrar os muros escolares e se desenvolvem de forma muito lenta na realidade escolar de ensino superior, quer nas instituições públicas, quer nas de ensino privadas. A realidade escolar dos cursos de Letras, segundo Bagno e Rangel (2005), em algumas instituições, costuma ter por base um currículo enrijecido, com um discurso normativo prescritivo sobre a língua.

Segundo Prados e Alvarez (2016), quanto à formação específica de professores dos cursos de Letras, um ponto a se considerar é o da dupla licenciatura, que acarreta um prejuízo ainda maior aos professores de Língua Estrangeira. Normalmente, privilegia-se a formação em Língua Portuguesa (mesmo com deficiências já mencionadas) e deixa-se pouco espaço no currículo para a Língua Estrangeira.

Não há cursos idênticos, no que se refere aos seus objetivos, nem mesmo currículos uniformes, de modo que se caracteriza uma gama de opções e situações divergentes. Em verdade, estudantes de Letras precisam conhecer os atuais resultados de estudos linguísticos, além dos estudos tradicionais (PRADOS; ALVAREZ, 2016).

É relevante o estudo sobre a língua falada, que, nos currículos de cursos de Letras, é voltado à aplicação de modelos da escrita à fala. Segundo Travaglia (2005), o estudante de Letras deveria ter uma postura de curiosidade frente ao fenômeno linguístico, de aceitar que modelos teóricos se transformam, mudam e que são limitados para análise de certos fatos linguísticos, ou ainda, podem ser descartados, com o passar do tempo e/ou com o advento de novas teorias.

Não é pertinente buscar explicações em um único modelo teórico, que é uma tradição comum nos estudos linguísticos e que pode limitar o trabalho do pesquisador, diminuindo, portanto, a significação social das pesquisas. Muitos profissionais que atuam nos cursos de 
Letras, de acordo com Travaglia (2005), têm dificuldade em reconhecer que a priorização do curso diz respeito à formação de docentes, em língua materna e/ou línguas estrangeiras, como já mencionado anteriormente.

\section{Práticas de Linguagem na contemporaneidade}

A sociedade contemporânea, com o rápido desenvolvimento tecnológico, em que se apresentam novas interações e novas práticas de linguagem, caracteriza-se pela transnacionalização das dimensões políticas e econômicas. Fabrício (2008) já apontava a hibridização do público e do privado, com a subjetividade consumista, o prazer imediato, o culto à aparência, com o consequente declínio da interioridade e da reflexividade como valores. E a BNCC (2018) destaca novas práticas de linguagem no contexto contemporâneo e nas atuais políticas de ensino.

E para Signorini (2012), no contexto contemporâneo, há novos letramentos, em ambientes multi e hipermidiáticos que, por sua vez, tornam-se desafios para o futuro professor de língua devido às diferentes práticas de uso da linguagem em sala de aula que consiste ainda em um letramento tradicional grafocêntrico. E Masetto (2012) já apontava a carência na formação do professor, já que não se prepara o professor para as atuais inovações, que não só incluem as tecnologias de informação e comunicação, mas novas interações e relações de linguagem. Ainda, para Masetto, a inovação se marca por projetos em movimento e a escola permanece estática.

Segundo a BNCC (2018), as práticas de linguagem contemporâneas envolvem, não só, novos gêneros e textos cada vez mais multissemióticos e multimidiáticos, mas também novos modos de produzir, de configurar, de disponibilizar, de replicar e de interagir. Também, as novas ferramentas para a edição de textos, como áudios, fotos e vídeos tornam acessíveis a qualquer pessoa a produção e disponibilização de textos multissemióticos nas redes sociais e em outros ambientes da Web.

Não só é possível acessar conteúdos variados em diferentes mídias, como também produzir e publicar fotos, vídeos diversos, podcasts, infográficos, enciclopédias colaborativas, revistas e livros digitais etc. Depois de ler um livro de literatura ou assistir a um filme, pode-se postar comentários em redes sociais específicas, seguir diretores, autores, escritores, acompanhar de perto seu trabalho; podemos produzir playlists, vlogs, vídeos-minuto, escrever fanfics, produzir e-zines, nos tornar um booktuber, dentre outras muitas possibilidades. Em tese, a Web é democrática: todos podem acessá-la e alimentá-la continuamente (BRASIL, 2018, p. 66). 
De acordo com o documento, apesar do espaço ser livre e bastante familiar para crianças, adolescentes e jovens, a escola não pode deixá-lo de lado, uma vez que se pressupõe a importância de se considerar as dimensões ética, estética e política desse uso, bem como saber lidar criticamente em relação aos conteúdos que circulam na Web. Além do fato de que, inicialmente, no ambiente, não há garantia quanto aos critérios editoriais e seleção do que é considerado adequado, bom e verdadeiro. Caracteriza-se, também, a viralização de publicações, o que possibilita fenômenos como o da pós-verdade, em que as opiniões importam mais do que os fatos em si (BRASIL, 2018).

Verifica-se que a escola, segundo esse discurso político-educacional, não pode se isolar e ignorar o fato de que as fronteiras entre o público e o privado estão sendo recolocadas.

\footnotetext{
Não se trata de querer impor a tradição a qualquer custo, mas de refletir sobre as redefinições desses limites e de desenvolver habilidades para esse trato, inclusive refletindo sobre questões envolvendo o excesso de exposição nas redes sociais. Em nome da liberdade de expressão, não se pode dizer qualquer coisa em qualquer situação. Se, potencialmente, a internet seria o lugar para a divergência e o diferente circularem, na prática, a maioria das interações se dá em diferentes bolhas, em que o outro é parecido e pensa de forma semelhante. Assim, compete à escola garantir o trato, cada vez mais necessário, com a diversidade, com a diferença (BRASIL, 2018, p. 66).
}

O discurso político-educacional traz, implícito, um discurso de responsabilidade da escola pela formação do educando que está inserido nesse novo contexto de novas práticas de linguagem, em que é necessário o desenvolvimento de uma postura crítica em relação ao que é publicado. A educação, segundo esses discursos, apresenta-se como um processo permanente, não só de construção de conhecimentos, das competências, do saber-fazer, mas também de construção de um leitor crítico, preparado para lidar com essas novas relações e práticas de linguagem.

Assim, evidencia-se o quanto é relevante uma reflexão sobre o currículo do curso de Letras, uma vez que este deve voltar-se à prioridade que é a de formar docentes de língua materna, ou de línguas estrangeiras, com uma educação linguística cientificamente consistente, de qualidade, adequada ao contexto contemporâneo.

\section{Reflexões sobre a formação do professor na área de Letras}

As Diretrizes Curriculares Nacionais (DCN), que estabelecem parâmetros para o projeto pedagógico de formação acadêmica e profissional e a carga horária para o curso de Letras, foram estabelecidas pela Resolução do Conselho Nacional de Educação (CNE-MEC) e Câmara 
da Educação Superior (CES-MEC) N N 18, publicada em 13 de março de 2002 (BRASIL, 2002c), fundamentada no Parecer CNE/CES N $\mathrm{N}^{\circ}$ 492, publicado em 03 de abril de 2001, retificado pelo Parecer CNE/CES No 1.363/2001, publicado em 29 de janeiro de 2002.

De acordo com as DCN, os cursos de graduação em Letras devem ter estruturas flexíveis para dispor ao profissional a ser formado opções de conhecimento e de atuação no mercado de trabalho. Segundo as diretrizes, o profissional em Letras deve ter domínio do uso da língua ou das línguas que sejam objeto de seus estudos, em termos de sua estrutura, funcionamento e manifestações culturais, além de ter consciência das variedades linguísticas e culturais.

Segundo essas diretrizes, o graduado em Letras, tanto em língua materna quanto em língua estrangeira, moderna ou clássica, nas modalidades de bacharelado ou de licenciatura, deve ser identificado por várias competências e habilidades, adquiridas em sua formação acadêmica convencional, teórica e prática, ou fora dela. Assim, dessa forma, com base nesse discurso, com vistas à formação de profissionais que dominem a língua estudada e suas culturas para atuarem como professores, pesquisadores, críticos literários, tradutores, intérpretes, revisores de textos, roteiristas, assessores culturais, entre outras atividades, o curso de Letras deve contribuir para o desenvolvimento de competências e habilidades, quanto ao domínio do uso da língua materna, ou de uma língua estrangeira, em suas manifestações oral e escrita, em termos de recepção e produção de textos.

Ao se falar da formação do professor de línguas estrangeiras, especificamente de Língua Inglesa é importante enfatizar a coexistência de dois tipos de formação: uma que envolve a aprendizagem e a outra o treinamento. A primeira envolve questões mais amplas das ciências da educação como a ética, o ensino reflexivo e emancipatório; a segunda, de cunho mais positivista, refere-se à aplicabilidade de técnicas de ensino nos mais variados contextos.

Vale ressaltar que nos cursos de Letras-Inglês têm-se comumente dois perfis de graduandos: aqueles alunos que já atuam como professores de Inglês e aqueles que ainda não possuem experiência docente, seja em escolas públicas ou privadas, regulares ou livres,

Os alunos-professores experientes já trazem às aulas da universidade saberes adquiridos pela prática diária com os seus alunos, já conhecem a organização curricular definida pelas escolas onde atuam e já estão se habituando ou já se habituaram aos problemas que precisam enfrentar quanto à condução dos conteúdos e para além deles. Para esses professores, o curso de Letras deixa de ser o primeiro contato com as particularidades da nova profissão e passa a ser um espaço de (re)construção dos seus saberes, da socialização dos saberes experienciais já existentes e da renovação dos saberes disciplinares trazidos pela universidade, agregando-os à experiência da sua prática de ensino. Nesse sentido, o curso de Letras, para esses alunos-professores experientes, deixa de ser o momento da formação inicial e passa a ter o status de formação contínua,

RPGE- Revista on line de Política e Gestão Educacional, Araraquara, v. 25, n. 1, p. 86-102, jan./abr. 2021. 
tudo isso, indicado pelos seus posicionamentos, modos de pensar e agir diante da profissão (SORTE, 2014, p. 541).

Segundo Ramirez (2014), não existe uma única e correta forma de se ensinar Inglês, ou qualquer outro idioma. Porém, a ascensão da Língua Inglesa à condição de língua internacional traz mudanças paradigmáticas para o seu ensino; algumas já estão em andamento, outras em fase de implementação e outras ainda não passam de construtos acadêmicos. Certo é que todas têm, ou terão, forte implicação no trabalho e na formação do docente.

Quanto aos conteúdos curriculares, esses devem estar ligados à área de Estudos Linguísticos e Literários e contemplar o desenvolvimento de competências e habilidades específicas, além da formação pedagógica. E quanto à carga horária, é necessário referenciar a Resolução CNE/CP No 1/2002 (BRASIL, 2002a) e a Resolução CNE/CP Nº 2/2002 (BRASIL, 2002b) que, respectivamente, instituem as Diretrizes Nacionais para Formação de Professores da Educação Básica, em nível superior, cursos de licenciatura e de graduação plena, duração e carga horária de tais cursos.

A Resolução CNE/CP N² 2/2002 estabeleceu que a carga horária mínima para os cursos de Licenciatura deve ter um total de 2.800 (duas mil e oitocentas) horas (BRASIL, 2002). Mas essa Resolução foi objeto de muita discussão na Comissão de Formação de Professores do CNE. Sua revogação foi proposta no Parecer CNE/CP N 5/2006, aprovado em abril de 2006 (BRASIL, 2006), com a determinação de que a carga horária mínima para os cursos de Licenciatura fosse de 2.800 (duas mil e oitocentas) horas, das quais, no mínimo 300 (trezentas) horas deveriam ser voltadas ao estágio supervisionado, e o mínimo de 2.500 (duas mil e quinhentas) horas voltadas às demais atividades formativas. Essa carga horária está em acordo com o art. 65, da Lei de Diretrizes e Bases da Educação Nacional, LDBEN No 9394, de 20 de dezembro de 1996 (BRASIL, 1996), que estabelece que a formação do docente, exceto para a educação superior, deve incluir a prática de ensino com, no mínimo, trezentas horas.

Quanto às licenciaturas, que formam professores de Educação Básica, para atuarem nos anos finais do ensino fundamental e no ensino médio, ou seja, o professor especialista, segundo Penin, Galian e Valdemarin (2014), após a LDBEN nº 9304/96 houve mudanças que alteraram a relação entre os conhecimentos que se referem aos fundamentos da educação e ao sistema educacional, disciplinas instrumentais e saberes de referência, quanto às diferentes áreas do conhecimento. Mesmo que o eixo da formação desse professor especialista situe-se no campo das áreas específicas, é cobrada uma articulação entre o específico e o pedagógico. E não é apenas uma relação temporal de sucessão da tradicional organização curricular, "conhecida 
como esquema ' $3+1$ ' - três anos de formação específica seguidos de um ano de formação pedagógica - que sobrevive em vários projetos de formação" (PENIN; GALIAN; VALDEMARIN, 2014, p. 57).

Para as autoras, mesmo que a competência básica do professor possa ser considerada como o domínio do conteúdo, apesar das indicações da literatura sobre formação, o desafio de um projeto de formação é romper com a dicotomia entre o conteúdo específico e sua dimensão pedagógica. Assim, evidencia-se a relevância do estudo da licenciatura, no currículo de Letras, pois é importante o domínio do saber de referência da área, dos estudos linguísticos de Língua Portuguesa ou de Língua Estrangeira, na qual o professor irá atuar. Esse professor deve ter clareza de como tais conteúdos podem ser transformados em objetos de ensino.

Segundo Penin, Galian e Valdemarin (2014), com base em outras pesquisas, em várias universidades federais do País, mais de $80 \%$ dos conteúdos das disciplinas, ainda, compõemse de estudos descritivos da língua, ou gramáticas prescritivas, segundo uma visão normativa da língua.

Segundo os discursos político-educacionais contemporâneos, focaliza-se o texto e seu contexto de produção de novas práticas de linguagem. Assim o ensino de línguas não pode estar desvinculado de seus usos.

Os projetos de formação em Letras, ou mesmo, cursos de licenciaturas de um modo geral, apresentam um discurso de formação para a inserção no mercado de trabalho. Ao término do curso, os futuros professores deveriam, também, conhecer e se apropriar das teorias linguísticas, além dos conhecimentos pedagógicos, a fim de que se fundamentem novas metodologias de ensino.

\section{Considerações finais}

Esse artigo limitou-se a uma discussão sobre os discursos subjacentes às políticas educacionais para uma reflexão sobre a formação docente do profissional de Letras, no quadro da educação contemporânea, em que se destacam discursos político-educacionais voltados às novas práticas de linguagem decorrentes de novas exigências da sociedade. Nos discursos político-educacionais são levantadas questões teóricas atuais sobre texto, gêneros discursivos, letramentos e multiletramentos, mas os professores, que atuam em sala de aula, carecem de fundamentação teórica específica em estudos do texto e do discurso, além de um aprofundamento nas bases pedagógicas, como o desenvolvimento de metodologias, da inserção das tecnologias de informação e comunicação aplicadas ao ensino.

RPGE- Revista on line de Política e Gestão Educacional, Araraquara, v. 25, n. 1, p. 86-102, jan./abr. $2021 . \quad$ e-ISSN:1519-9029 DOI: https://doi.org/10.22633/rpge.v25i1.13628 
Com base nos discursos manifestados nas políticas educacionais, um projeto de formação de professor na área de Letras deveria se pautar em questionamentos sobre a meta prioritária do curso: se este deve ser voltado à formação de um usuário competente da língua, ou à formação de um especialista, segundo estudos linguísticos, sobre concepções de língua e de gramática, do papel da norma e das variações linguísticas, para atender às políticas culturais, educacionais e didático-pedagógicas. O processo de ensino-aprendizagem de línguas retoma, em princípio, diferentes visões das teorias linguísticas, sem que se tenha consciência disso.

As condições de produção específicas que regem a interpretação da linguística, em termos teórico-metodológicos, em sala de aula, são as que se apreendem do momento históricosocial em que seu uso se situa. Para o futuro professor de línguas, além de teorias linguísticas aplicadas ao ensino, de análise do discurso, de crítica literária, a formação específica e a formação pedagógica devem se articular para atender às orientações dos documentos oficiais, que trazem discursos político-educacionais voltados às novas práticas de linguagem e responsabilidade da escola no cenário contemporâneo.

Verificou-se que as políticas educacionais e linguístico-culturais nos projetos de formação do profissional de Letras refletem discursos, determinados no processo histórico da educação brasileira e delimitados no contexto contemporâneo. O discurso de formação do professor de línguas, portanto, considerando-se o contexto social em que esse profissional se insere, com as novas práticas de linguagem e novas políticas educacionais, deveria estar em processo de reformulação e considerar constante processo de mudança. Evidencia-se, assim, cada vez mais, a necessidade de uma formação contínua para o professor.

\section{REFERÊNCIAS}

BAGNO, M. Curso de Letras? Pra quê? Revista Língua Portuguesa, Conhecimento Prático, n. 40, p. 16-23, abr. 2013. Disponível em:

https://forumms.wordpress.com/2013/02/13/curso-de-letras-pra-que-marcos-bagno/. Acesso em: 16 nov. 2018.

BAGNO, M.; RANGEL, E. O. tarefas da educação linguística no Brasil. Revista de Linguística Aplicada, v. 5, n. 1, 2005. Disponível em: http://www.scielo.br/pdf/rbla/v5n1/04.pdf. Acesso em: 18 out. 2018.

BAUMAN, Z. Capitalismo parasitário. Trad. De Eliana Aguiar. Rio de Janeiro: Zahar, 2010. 
BRASIL. Secretaria da Educação Nacional. Lei de Diretrizes e Bases da Educação Nacional No 9394. Brasília: Ministério da Educação, 20 dez. 1996. Disponível em: https://www2.senado.leg.br/bdsf/bitstream/handle/id/70320/65.pdf. Acesso em: 22 set. 2018.

BRASIL. Secretaria da Educação Básica. Parâmetros Curriculares Nacionais (PCN). Brasília: MEC, 1998. Disponível em:

http://portal.mec.gov.br/seb/arquivos/pdf/introducao.pdf. Acesso em: 12 set. 2018.

BRASIL. Conselho Nacional de Educação. Parecer CNE/CES No 492. Diretrizes Curriculares Nacionais dos cursos de Filosofia, História, Geografia, Serviço Social, Comunicação Social, Ciências Sociais, Letras, Biblioteconomia, Arquivologia e Museologia. Brasília: CNE, 3 abr. 2001. Disponível em: http://portal.mec.gov.br/cne/arquivos/pdf/CES0492.pdf. Acesso em: 23 nov. 2018.

BRASIL. Conselho Nacional de Educação. Parecer CNE/CES n. 1363/2001. Diretrizes Curriculares Nacionais dos Cursos de Filosofia, História, Geografia, Serviço Social, Comunicação Social, Ciências Sociais, Letras, Biblioteconomia, Arquivologia e Museologia. Brasília: CNE, 29 jan. 2002. Disponível em: http://portal.mec.gov.br/cne/arquivos/pdf/2001/pces1363_01.pdf. Acesso em: 11 nov. 2018.

BRASIL. Conselho Nacional de Educação. Resolução CNE/CES N 1. Brasília: CNE, 18 fev. 2002a. Disponível em: http://portal.mec.gov.br/cne/arquivos/pdf/rcp01_02.pdf. Acesso em: 12 mar. 2019.

BRASIL. Conselho Nacional de Educação. Resolução CNE/CES No 2. Brasília: CNE, 19 fev. 2002b. Disponível em: http://portal.mec.gov.br/cne/arquivos/pdf/CP022002.pdf. Acesso em: 21 mar. 2019.

BRASIL. Conselho Nacional de Educação. Câmara da Educação Superior. Resolução CNE/CES N¹8. Brasília: CNE, 9 abr. 2002c. Disponível em: http://portal.mec.gov.br/cne/arquivos/pdf/CES182002.pdf. Acesso em: 15 nov. 2018.

BRASIL. Secretaria da Educação Básica. Orientações Curriculares Nacionais do Ensino Médio. Linguagens, Códigos e suas Tecnologias. Brasília: MEC, 2006. Disponível em: http://portal.mec.gov.br/seb/arquivos/pdf/book_volume_01_internet.pdf. Acesso em: 22 out. 2018.

BRASIL. Secretaria da Educação Básica. Base Nacional Comum Curricular (BNCC). Brasília: MEC, 14 de dezembro de 2018. Disponível em: $\mathrm{http} / / /$ basenacionalcomum.mec.gov.br/images/BNCC_EI_EF_110518_versaofinal_site.pdf. Acesso em: 10 fev. 2019.

CAVALCANTI, J. R. As faces de uma polêmica: o episódio do livro didático Por uma vida melhor. DELTA: Documentação de Estudos em Linguística Teórica e Aplicada, v. 29, n. esp., p. 485-501. 2013. Disponível em:

http://www.scielo.br/scielo.php?script=sci_arttext\&pid=S0102-

$44502013000300007 \& \operatorname{lng}=$ en\&nrm=iso. Acesso em: 14 set. 2018. 
FABRICIO, B. F. Linguística Aplicada como espaço de desaprendizagem - redescrições em curso. In: MOITA LOPEZ, L. P. (org.). Por uma linguística Aplicada Indisciplinar. São Paulo: Parábola Editora, 2006. p. 45-63.

GERALDI, J. W. Correlações entre as situações políticas e as preocupações com a Língua Portuguesa. In: CINTRA, A. M. M. Ensino de Língua Portuguesa: reflexão e ação. São Paulo: EDUC, 2008.

MAINGUENEAU, D. Cenas da enunciação. São Paulo: editora Parábola, 2008.

MASETTO, M. T. Inovação Curricular, tecnologias de informação e comunicação e formação de professores. In: SIGNORINI, I.; FIAD, R. S (Org.). Ensino de língua. Das reformas, das inquietações e dos desafios. Belo Horizonte: Editora UFMG, 2012. p. 230-247.

PAIVA, V. L. M. O. Avaliação dos cursos de Letras e a formação do professor. Revista do GELNE, v. 5, n. 1-2, 2003. Disponível em:

https://periodicos.ufrn.br/gelne/article/view/11722. Acesso em: 15 nov. 2018.

PENIN, S. T. S; GALIAN, C. V. A; VALDEMARIN, V. Currículos de Formação de Professores de Língua Portuguesa: instituições autônomas e o poder de sua história. Revista Brasileira de Estudos Pedagógicos, Brasília, v. 95, n. 239, p. 55-72, jan./abr. 2014. Disponível em: http://www.scielo.br/pdf/rbeped/v95n239/a04v95n239.pdf. Acesso em: 14 dez. 2018.

PRADOS, R. M. N.; ALVAREZ, S. M. Ensino da Língua Materna no Brasil: políticas públicas e reflexões sobre o curso de Letras. Revista Linguagem\& Ensino, v. 19, n. 1, p. 125-143, 2016.

PRADOS, R. M. N.; BONINI, L. M. M. Ensaios de semiótica aplicada. Curitiba PR: editora CRV, 2017.

RAMIREZ, R. A. Histórias de vida na formação do professor. São Paulo-SP: editora CEETEPS, 2014.

SIGNORINI, I. Letramentos multi-hipermidiáticos e formação de professores de língua. In: SIGNORINI, I.; FIAD, R. S. (Org.). Ensino de língua. Das reformas, das inquietações e dos desafios. Belo Horizonte: Editora UFMG, 2012. p. 282-303.

SORTE, P. B. Por que a graduação em Letras-Inglês pode ter o status de formação contínua? Revista Brasileira de Linguística Aplicada, v. 15, n. 3, 2015. Disponível em: http://www.scielo.br/pdf/rbla/v15n3/1984-6398-rbla-15-03-00537.pdf. Acesso em: 25 abr. 2019.

SOUZA, G. S.; PEREIRA, C. C.; COSTA, E. A. A formação do professor em cursos de Letras: aspectos do objeto de ensino em disciplinas da área de língua portuguesa. Letras, Santa Maria, v. 22, n. 44, p. 197-211, jan./jun. 2012. Disponível em: https://periodicos.ufsm.br/letras/article/view/12197/7591. Acesso em: 12 dez. 2018. 


\section{Como referenciar este artigo}

PRADOS, R. M. N.; RAMIREZ, R. A.; ALVAREZ, S. M. Reflexões sobre políticas educativas, BNCC e formação docente. Revista on line de Política e Gestão Educacional, Araraquara, v. 25, n. 1, p. 86-102, jan./abr. 2021. e-ISSN:1519-9029. DOI: https://doi.org/10.22633/rpge.v25i1.13628

Submetido em: 29/04/2020

Revisões requeridas em: 26/06/2020

Aceito em: 10/09/2020

Publicado em: 02/01/2021 